\title{
Rupture of endotracheal tube cuff during robot-assisted endoscopic thyroidectomy
} -A case report-

\author{
Hyung-Chul Lee ${ }^{1}$, Mi-Ja Yun², Eui-Kyoung Goo ${ }^{3}$, Jae-Hyon Bahk ${ }^{1}$, Hee-Pyoung Park ${ }^{1}$, Young-Tae Jeon ${ }^{3}$, \\ and Sang Chul Lee ${ }^{1}$
}

Department of Anesthesiology and Pain Medicine, ${ }^{1}$ Seoul National University Hospital, ${ }^{2}$ National Medical Center, Seoul, ${ }^{3}$ Seoul National University Bundang Hospital, Seongnam, Korea

We encountered a case of a rupture of an endotracheal tube cuff during robot-assisted thyroid surgery in a 35-yearold male patient. Two hours after commencing surgery, the bellows of the ventilator were not filled and a rupture of the endotracheal tube cuff was suspected. Once the robot-manipulator is engaged, the position of the operating table cannot be altered without removing it from the patient. Reintubation with direct laryngoscopy was performed with difficulty in the narrow space between the patient's head and robot-manipulator without moving the robot away from the patient. The rupture of the endotracheal tube cuff was confirmed by observing air bubbles exiting from the balloon in water. The patient was discharged 3 days after surgery without complications. In robot-assisted thyroid surgery, a preoperative arrangement of the robot away from the patient's head to obtain easy access to the patient is essential for safe anesthetic care. (Korean J Anesthesiol 2010; 59: 416-419)

Key Words: Anesthesia, Complication, Minimally invasive surgery, Robotic-assisted surgery, Thyroid surgery.

While robot-assisted endoscopic surgery has many advantages, such as smaller incision and magnified 3-dimensional view, it also presents additional anesthetic concerns. These include prolonged surgical time with carbon dioxide insufflation, bulky robotic instruments in the patient's body cavity, limited access to the patient's airway and invasion of the anesthetic workspace [1]. Restrictive access to the patient's airway can be a hindrance that delays resuscitation during airway emergencies in robot-assisted endoscopic thyroid surgery. There are few reports on the risk of tracheal injury and the need for the appropriate preoperative arrangement of the robot and operating table to allow easy access to the patient during emergencies, even though the use of robot-assisted surgery has increased recently.

This paper reports a case of an abrupt ventilatory insufficiency due to rupture of an endotracheal tube cuff during robot-

Received: January 19, 2010. Revised: 1st, February 1, 2010; 2nd, March 19, 2010. Accepted: March 24, 2010.

Corresponding author: Mi-Ja Yun, M.D., Department of Anesthesiology and Pain Medicine, National Medical Center, 243, Eulji-ro, Jung-gu, Seoul 100-799, Korea. Tel: 82-2-2260-7372, Fax: 82-2-2262-4766, E-mail: anemjy@lycos.co.kr

(c) This is an open-access article distributed under the terms of the Creative Commons Attribution Non-Commercial License (http:// creativecommons.org/licenses/by-nc/3.0/), which permits unrestricted non-commercial use, distribution, and reproduction in any medium, provided the original work is properly cited. 
assisted endoscopic thyroid surgery with a review of the relevant literature on the cause, prevention and management of this condition.

\section{Case Report}

A 35-year-old man, $179.9 \mathrm{~cm}$ in height and $84.8 \mathrm{~kg}$ in weight, who was diagnosed with a papillary thyroid carcinoma presented for a robot (da Vinci Surgical System ${ }^{\mathrm{TM}}$, Intuitive Surgical, Inc., Sunnyvale, CA, USA)-assisted endoscopic total thyroidectomy. In computed tomography, a $5 \mathrm{~mm}$ sized nodule was found at the right thyroid. His medical history was unremarkable and the preoperative electrocardiogram (ECG), laboratory examination and chest radiography were normal.

The patient was brought to the operating room where routine monitors (ECG, pulse oximetry, and noninvasive blood pressure) were applied. After adequate preoxygenation, anesthesia was induced with lidocaine $30 \mathrm{mg}$, propofol $120 \mathrm{mg}$ and rocuronium $50 \mathrm{mg}$. The patient's trachea was intubated without difficulty with an ID $7.5 \mathrm{~mm}$ cuffed reinforced endotracheal tube (Safety-Flex ${ }^{\mathrm{TM}}$, Mallinckrodt Medical Ltd., Athlone, Ireland) and the tracheal cuff was inflated. The proper placement of the tube was confirmed by external palpation of the tracheal cuff in the suprasternal notch. The endotracheal tube was fixed with adhesive tape on the right side of the mouth at the $23 \mathrm{~cm}$ mark. After auscultation of both lung fields, pressure-controlled mechanical ventilation was started with an inspiratory pressure of $16 \mathrm{cmH}_{2} \mathrm{O}$. Anesthesia was maintained with desflurane 4-6 vol\%, oxygen in air $\left(\mathrm{FiO}_{2}=0.5\right)$ and a continuous infusion of remifentanil with an effect-site concentration between 0.5 and $4.5 \mathrm{ng} / \mathrm{ml}$. The driving inspiratory pressure and respiration rate were adjusted to maintain an end-tidal $\mathrm{CO}_{2}$ between 35 and 40 mmHg.

The patient was placed in the supine position with head extension and neck flexion, and the robot arms were inserted into the patient via the bilateral axillary breast approach (Fig. 1) [2]. The $\mathrm{CO}_{2}$ insufflation pressure was maintained at $6 \mathrm{cmH}_{2} \mathrm{O}$ throughout the procedure. Two hours after commencing the operation, the tidal volume decreased abruptly to $183 \mathrm{ml}$ with an inspiration pressure set to $17 \mathrm{cmH}_{2} \mathrm{O}$, and the bellows of the ventilator was not filled adequately. The hemodynamic variables were not changed. Controlled ventilation was switched immediately to manual ventilation and the oxygen flow was increased. The pilot balloon of the endotracheal tube was inflated but the anesthetic bag was not filled completely. Reintubation was planned under the suspicion of a tracheal injury and a rupture of the endotracheal tube cuff. An attempt was made to move the robot manipulator with arms away from the patient's head to make space for reintubation but it could not be moved unless the robot arms were removed from the patient (Fig. 2). An attempt was made to replace the ruptured

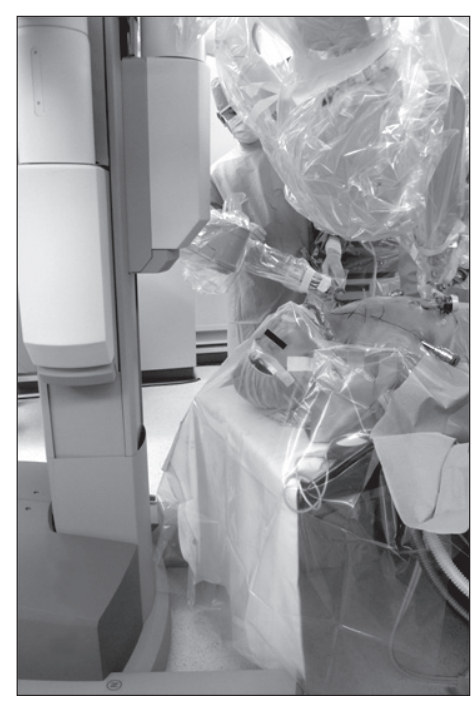

Fig. 2. Arrangement of the robot-manipulator is shown. The access to the patient's airway is limited once the robot arms are engaged.
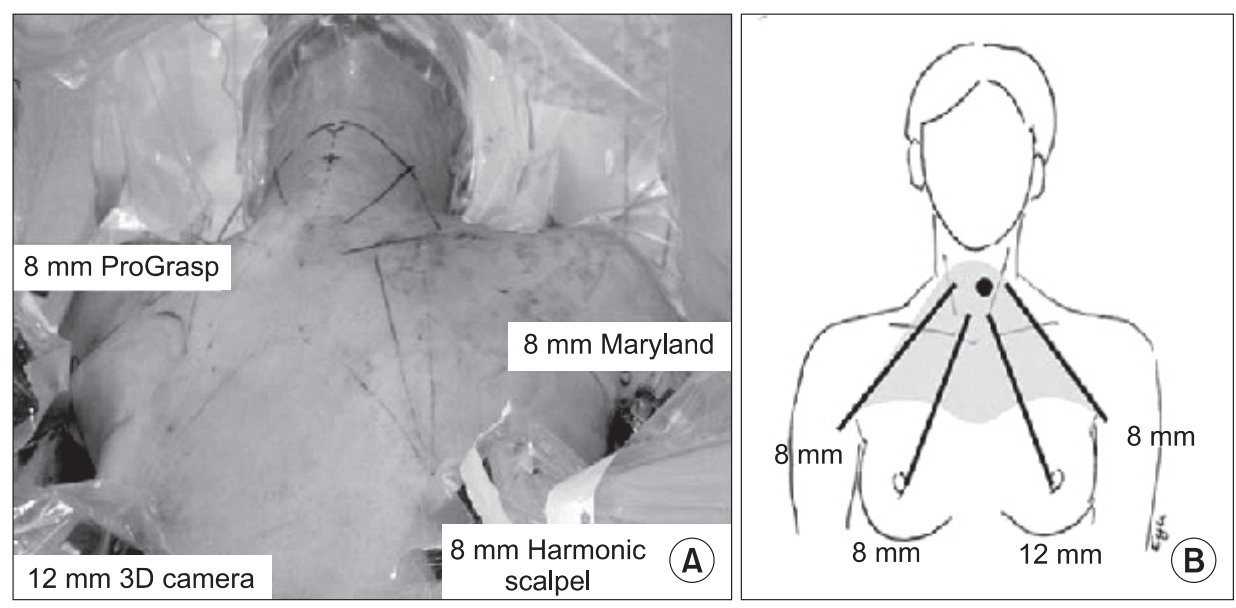

Fig. 1. A photographic (A) and schematic (B) illustration of the ports and paths of the instruments in bilateral axillary breast approach technique in robotassisted endoscopic thyroidectomy is shown. (A) $8 \mathrm{~mm}$ ProGrasp forceps; $12 \mathrm{~mm}$ 3D camera; $8 \mathrm{~mm}$ Harmonic scalpel; $8 \mathrm{~mm}$ Maryland dissector (reproduced with permission from Fig. 1 in Lee et al. [2]). 
endotracheal tube with a new one using a tube exchanger at the right side of the patient's head due to the small space between the robot-manipulator and patient's head, but it was unsuccessful because the new tube was blocked at the vocal cord level. Therefore, the tube exchanger was removed and face mask ventilation was applied to the patient. The surgical team was asked to change the position of the operating table to make more space for reintubation. However, once the robotmanipulator is engaged, the position of the operating table cannot be changed without removing it from the patient. Removing the robot from the patient requires several steps and takes 1-2 minutes [1]. Therefore, reintubation was attempted in the small space between the patient's head and robotmanipulator without moving the robot away from the patient because the patient's airway was not difficult (Cormack grade I) during anesthetic induction. Fortunately, reintubation under direct laryngoscopy was successful at the first attempt while the surgery drape over patient's head was lifted up. The elapsed time was approximately $1-2$ minutes for this process. During the reintubation, the peripheral oxyhemoglobin saturation $\left(\mathrm{SpO}_{2}\right)$ was not decreased from 99 or $100 \%$, and the maximum end tidal $\mathrm{CO}_{2}$ was $41 \mathrm{mmHg}$. The rupture of the endotracheal tube cuff was confirmed by observing air bubbles exiting from two points of $2-3 \mathrm{~mm}$ sized lacerations on the lower part of the balloon in water (Fig. 3).

After reintubation, ventilation was normalized without signs of pneumothorax or pneumomediastinum, such as a decrease in tidal volume and oxygen saturation. No changes in blood pressure or heart rate were observed. The tidal volume was maintained between 532 and $550 \mathrm{ml}$ with an inspiration pressure set to 16 or $17 \mathrm{cmH}_{2} \mathrm{O}$ until the end of the operation. The surgeon was asked to flush the lesion with saline to find any air leakage from the tracheal injury site but he completed the operation instead.

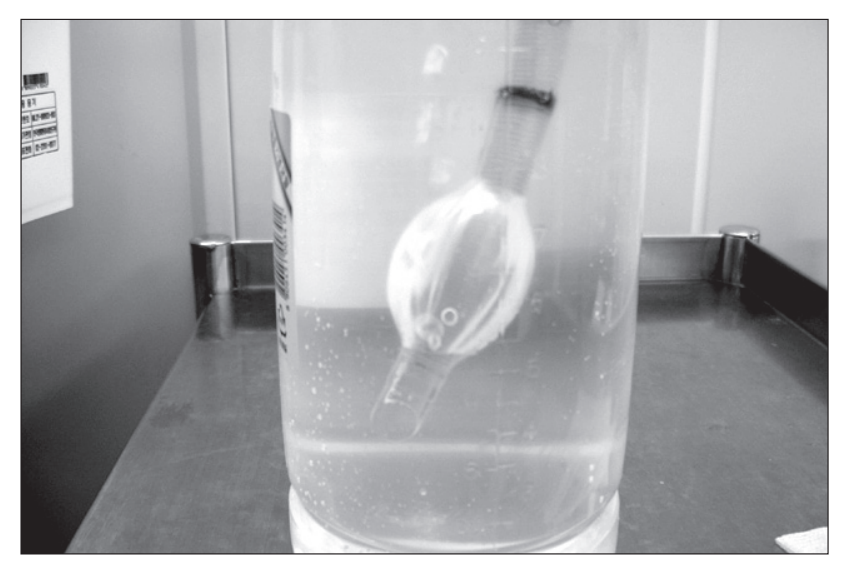

Fig. 3. The air bubbles coming out of the lower parts of endotracheal tube cuff are seen. There were two points of $1-2 \mathrm{~mm}$ sized lacerations on lower part of the cuff.
After surgery, muscle relaxation was reversed and the patient resumed spontaneous ventilation and opened his eyes. He did not present with chest discomfort or dyspnea, and his blood pressure and heart rate were within the normal range. The patient was extubated and transported to the postanesthesia care unit (PACU). The duration of surgery and anesthesia were 4 hours 30 minutes and 5 hours 10 minutes, respectively. The crystalloid volume administered, estimated blood loss and urine output during surgery were 1,400 ml, $100 \mathrm{ml}$ and $850 \mathrm{ml}$, respectively.

In the PACU, there were no subjective symptoms, such as cough, dyspnea and chest pain. The physical examination did not reveal any oxygen desaturation or other signs of subcutaneous emphysema. Subcutaneous emphysema, pneumothorax or pneumomediastinum were not observed on the chest X-rays taken on the first and second postoperative days. He showed no signs of infection including fever, cough and sputum while he was at hospital. He was discharged without complications 3 days after surgery.

\section{Discussion}

In a recent review, tracheal injury occurs in less than one in every 1,000 thyroid operations [3]. However, some authors are concerned that it happens more often than reported [4]. A lack of haptic feedback [5], and a prolonged operation time for robot-assisted surgery can increase the risk of tracheal injury. To our knowledge, this is the first reported case of endotracheal tube cuff laceration during robot assisted thyroidectomy. Kang et al. [6] reported no case of tracheal injury in first 100 robotassisted endoscopic surgery for thyroid cancer.

Tracheal injury during thyroid surgery can be a life threatening condition, such as massive subcutaneous emphysema, neck abscess, mediastinitis, pneumothorax, cardiac tamponade, and tension pneumomediastinum [7]. Cases of death from sudden respiratory distress and infection have also been reported [4]. In our case, sudden ventilatory insufficiency due to an endotracheal cuff rupture was noticed immediately after it occurred. The uniqueness of this case is that it happened during robot-assisted endoscopic surgery, which adds many anesthetic considerations when managing an airway emergency.

The signs of tracheal injury during a thyroidectomy vary according to the laceration site. When the tracheal injury is below the endotracheal tube cuff, it can induce subcutaneous emphysema and pneumothorax due to positive ventilation [8]. However, the tracheal injury at the cuff level might cause a rupture of the endotracheal tube cuff, which can lead to mechanical ventilatory failure during anesthesia [9] and abrupt pneumothorax after extubation [10]. Above the cuff level, such an injury may not manifest any clinical signs but insufflated $\mathrm{CO}_{2}$ 
may move to the oral cavity $[11,12]$.

When an injury to the trachea is suspected during surgery, a visual inspection of the operation field may miss small perforations. Instilling saline into the wound and checking for air leakage is recommended. A flexible bronchoscope can be used to confirm the injury. A chest X-ray was used to identify pneumothorax or pneumomediastinum, and computed tomography of the neck and chest may help localize the site of the perforation. In our case, the tracheal injury sites were neither visualized nor confirmed by saline instillation. However, the abrupt onset of ventilatory failure and the observation of two lacerations on the endotracheal cuff were sufficient to prove the tracheal injuries in this case.

For treatment, primary repair is the first choice [11,12]. A strap muscle can be rotated over and reinforce the repair. Conservative treatment is considered appropriate for small lacerations of the membranous trachea, less than one third of the circumference of the trachea or bronchus.

A bronchoscopic examination could have been used to confirm the tracheal injury but the securing the airway was the primary concern at that time. It would be difficult to identify the tracheal injury site by bronchoscopy because it was sealed by the cuff of the reintubated endotracheal tube.

The robotic surgical system consists of three components: a master console, a robotic surgical manipulator and a standard computer/visualization tower. Ample space in the room is essential so the robot can be moved out of the way easily and without obstructions. The robotic surgical manipulator contains four arms. The one arm inserted into the patient via the right breast holds a stereoscopic camera, while the other three arms are designed to hold the interchangeable instruments, such as forceps or coagulator in our case.

Although the risk of cardiopulmonary emergencies is not increased in robot-assisted procedures, their treatment is more complicated. Once the robot-manipulator is engaged, the position of the operating table cannot be changed without removing the robot from the patient's side. Removing the robot requires disengagement of the instruments and camera from the robot arms, unlatching the arms from the trocars, and then backing the robot away from the patient [1]. In our case, reintubation was attempted in the small space between the patient head and robot-manipulator without moving the robot away from the patient because a difficult airway was not expected. However, if a difficult airway is expected, the robot must be removed as quickly as possible to allow unimpeded access to the airway.

Adequate workspace for the anesthesiologist after the robot is brought into position is another concern. This problem should be solved by turning the head of the bed $30^{\circ}$ to the robot's side, which allows the anesthesiologist unimpeded access to one side of the head and the un-tucked arm [1]. In our case, we asked the surgical team to turn the head of the bed $30^{\circ}$ to the robot's side for the subsequent robot-assisted operation, but they insisted that the robot-manipulator with arms should be located in line with the arm holding the 3D camera. This parallel arrangement of the robot-manipulator with the patient makes it difficult to prepare adequate workspace for the anesthesiologist.

In conclusion, limited access to the patient's airway and neck by robotic instruments locked over the patient's head can cause a delay in treating sudden emergencies that can occur during anesthesia. Therefore, in robot-assisted endoscopic thyroid surgery, the preoperative arrangement of the robot manipulator with the arms away from patient's head and mandatory saline instillation before the completion of surgery should be considered for safe anesthetic care.

\section{References}

1. Parr KG, Talamini MA. Anesthetic implications of the addition of an operative robot for endoscopic surgery: a case report. J Clin Anesth 2002; 14: 228-33.

2. Lee KE, Rao J, Youn YK. Endoscopic thyroidectomy with the da Vinci robot system using the bilateral axillary breast approach (BABA) technique: our initial experience. Surg Laparosc Endosc Percutan Tech 2009; 19: e71-5.

3. Gosnell JE, Campbell P, Sidhu S, Sywak M, Reeve TS, Delbridge LW. Inadvertent tracheal perforation during thyroidectomy. Br J Surg 2006; 93: 55-6.

4. Iacconi P. Inadvertent tracheal perforation during thyroidectomy $(\mathrm{Br}$ J Surg 2006; 93: 55-56). Br J Surg 2006; 93: 770-1.

5. van der Meijden OA, Schijven MP. The value of haptic feedback in conventional and robot-assisted minimal invasive surgery and virtual reality training: a current review. Surg Endosc 2009; 23: 118090.

6. Kang SW, Jeong JJ, Nam KH, Chang HS, Chung WY, Park CS. Robotassisted endoscopic thyroidectomy for thyroid malignancies using a gasless transaxillary approach. J Am Coll Surg 2009; 209: e1-7.

7. Chauhan A, Ganguly M, Saidha N, Gulia P. Tracheal necrosis with surgical emphysema following thyroidectomy. J Postgrad Med 2009; 55: 193-5.

8. Gries CJ, Pierson DJ. Tracheal rupture resulting in life-threatening subcutaneous emphysema. Respir Care 2007; 52: 191-5.

9. Park HS, Lee SI, Shin HW, Choi SU, Park JY, Lee HW, et al. Tracheal laceration detected by high end-tidal $\mathrm{CO}_{2}$ during endoscopic thyroidectomy. Korean J Anesthesiol 2009; 56: 703-5.

10. Choi WJ, Park YS, Jeong SM, Ku SW, Park PH. Bilateral pneumothorax induced by tracheal injury during total thyroidectomy with modified radical neck dissection: a case report. Korean J Anesthesiol 2007; 53: 399-402.

11. Damrose EJ, Damrose JF. Delayed tracheal rupture following thyroidectomy. Auris Nasus Larynx 2009; 36: 113-5.

12. Pandey CK, Singh N, Goyal P, Agarwal A. Tracheal injury during endoscopic hemithyroidectomy. J Laparoendosc Adv Surg Tech A 2001; 11 : 43-6. 